\title{
Perception and Healthcare seeking practices regarding dysmenorrhea among public secondary school students in Lagos, Nigeria
}

\author{
Oluwole $\mathrm{EO}^{1}$, Agha $\mathrm{OO}^{1}$, Ogunyemi $\mathrm{AO}^{1}$, Bakare $\mathrm{OQ}^{2}$
}

${ }^{1}$ Department of Community Health and Primary Care, College of Medicine, University of Lagos, Lagos, Nigeria.

${ }^{2}$ Department of Community Health and Primary Health Care, Lagos State College of Medicine, Ikeja, Lagos, Nigeria.

Submitted: $13^{\text {th }}$ August 2020

Accepted: $30^{\text {th }}$ September 2020

Published: $30^{\text {th }}$ December 2020

\begin{abstract}
Objectives: Dysmenorrhea is an important health problem which may have a negative impact on female health, school activities and psychological status. This study assessed the prevalence, knowledge, perception and healthcare seeking practices of dysmenorrhea among secondary school students in Lagos State, Nigeria. The pattern of management of dysmenorrhea among respondents was also assessed.

Methods: A cross-sectional descriptive survey was conducted among 420 adolescents in public secondary schools in Ikeja Local government area of Lagos State, Nigeria. Respondents were interviewed using a structured pretested questionnaire. Data was analyzed with SPSS Version 22.0. The level of statistical significance was set at $p \leq 0.05$. Results: Mean \pm SD age at menarche was $12.3 \pm 1.3$ years. The prevalence of dysmenorrhea among respondents was $75.2 \%$. About one-quarter $106(25.2 \%)$ had good knowledge and $209(49.8 \%)$ had good perception of dysmenorrhea. Only $10 \%$ had ever sought health care for dysmenorrhea. A statistically significant association was found between the knowledge of respondents and healthcare-seeking behavior towards dysmenorrhea $(p=0.004)$. Conclusion: The prevalence of dysmenorrhea was high and majority of respondents had poor knowledge. Improving adolescents' knowledge of dysmenorrhea through health education could positively influence their health care-seeking behavior.
\end{abstract}

Key words: Dysmenorrhea, knowledge, prevalence, perception, secondary school students, healthcare-seeking practices, adolescents.

\section{Plain English summary}

Dysmenorrhea, also known as menstrual pain, is an important health problem that may negatively impact health, school activities, and psychological status. It affects about $60-90 \%$ of adolescents and it is often considered a natural occurrence of the menstrual cycle, therefore very few seek treatment. This study aimed to assess the prevalence, knowledge, perception, and healthcare-seeking practices towards dysmenorrhea among adolescents in public secondary schools in Ikeja LGA, Lagos State. The pattern of management of dysmenorrhea among respondents was also assessed. It was a cross-sectional descriptive survey conducted among 420 secondary school students. Respondents were interviewed using a structured pre-tested questionnaire and data was analyzed using SPSS version 22.0. The median age and interquartile range (IQR) of the respondents were $15(14-16)$ years. The mean \pm SD age at menarche 
among the respondents was $12.3 \pm 1.3$ years. Dysmenorrhea was reported by $75.2 \%$ of them. About onequarter $(25.2 \%)$ of the respondents had good knowledge of dysmenorrhea and $209(49.8 \%)$ had a good perception of dysmenorrhea. Only $10 \%$ of respondents had ever sought health care for dysmenorrhea. Knowledge of respondents was found to influence health-seeking behavior, therefore, improving adolescent's knowledge about menstrual pain through health education could positively influence their healthcare-seeking behavior.

\section{Background}

Menstruation is a physiological process that involves the monthly discharge of blood, mucus, and epithelial cells from the uterus and its onset is an important milestone in the process of growth and development that prepares young women for motherhood $(1,2,3)$. It is a natural event that occurs throughout the reproductive years of women. Most females experience some degree of pain and discomfort when going through menstruation (4). Dysmenorrhea, also known as menstrual pain, refers to painful cramps during menstruation which may be mild, moderate to severe in intensity The pain may sometimes radiate to other parts of the body such as the legs (5). It is the commonest gynecological complaint among adolescents and young adult females (4). Adolescence is a transitional phase of growth and development between childhood and adulthood. The World Health Organization defines adolescents as individuals in the 10-19 years' age group (6). It is sometimes a very difficult time for young people with rapid growth and development, with risks to health and well-being. It is the time when major physical changes take place and differences between boys and girls are highlighted (7). It involves puberty with the occurrence of thelarche, pubarche, and menarche. The normal menstrual cycle depends on composite interactions between the hypothalamus, pituitary, ovaries, and endometrium. Abnormalities in any of these organs can result in menstrual dysfunction. Menstrual disorders affect up to $75 \%$ of adolescents and is a common reason for seeking medical attention (8).

Dysmenorrhea usually commences shortly after the onset of menstruation, and usually improves with age; but sometimes it starts later in life, most likely due to an underlying causative condition (2).

Premenstrual symptoms which include tenderness of breasts, swollen abdomen, and others usually precede the onset of menstruation and may continue throughout the period $(8,9)$.

Dysmenorrhea occurs as sharp, intermittent pain, or dull aching pain or cramps in the lower abdominal or pelvic region, and may also involve lower back pain or a pulling sensation in the inner thighs. Other symptoms associated with the pain include headaches, dizziness/fainting attack, vomiting, nausea, diarrhea, or constipation. The symptoms and severity differ from one person to another in relation to age, smoking habits, body weight, early menarche, menstrual flow, family history of dysmenorrhea, and other risk factors. The pain usually starts shortly before or during the menstrual period, peaks after a day, and subsides after 2-3 days $(1,10)$. Dysmenorrhea is an important problem that may negatively impact female health, social relationships, school or work activities, and psychological status $(5,11)$.

Three types of dysmenorrhea have been described. Primary dysmenorrhea, also called spasmodic dysmenorrhea, refers to pain in the lower abdomen just before or during menstruation in the absence of any identifiable pathological condition, while secondary dysmenorrhea starts after an initial period of painfree menstruation and is usually associated with a pelvic pathology such as endometriosis, uterine leiomyoma, pelvic inflammatory disease, ovarian cyst, intrauterine device and cervical stenosis (12). The least common type is the membranous dysmenorrhea which is the pain following the passage of a uterine cast, usually due to endometritis and commonly seen in younger women (10).

Dysmenorrhea is common among young females and affects about $60-90 \%$ of adolescents. It may be severe enough to interfere with daily activities in about $20 \%$ of affected women, but symptoms have been found to improve with increasing age, or childbirth $(2,13,14)$. Researches have documented various impacts of dysmenorrhea among women of reproductive age. It is a leading cause of absenteeism from school or work, poor concentration, social withdrawal, and decreased academic performance with reduced quality of life and general well-being $(14,15,16)$. Despite these debilitating consequences of dysmenorrhea, it has been found that only a few women and adolescents seek treatment (17). Previous studies have revealed limited knowledge and wrong perception of menstruation and dysmenorrhea among Nigerian adolescents (18). Affected adolescents may therefore seek help from wrong sources, leading to wrong advice and 
inappropriate treatment. There is a paucity of data on perception and healthcare-seeking behavior towards dysmenorrhea among secondary school students in our environment. Hence, this study was carried out to assess the prevalence, knowledge, perception, and healthseeking practices towards dysmenorrhea among adolescents in public secondary schools in Lagos, Nigeria. We also assessed the pattern of management of dysmenorrhea among respondents.

\section{Methodology}

\section{Study location}

Ikeja is one of the twenty Local Government Areas (LGA) in Lagos state. It is located at 49.2 $\mathrm{km}$ northwest of Lagos, South-Western Nigeria. Ikeja LGA has 3 divisions (Ikeja, Ojodu, and Onigbongbo LCDA) with a total of 18 wards and a population of 648,720 as of the 2006 census. There are six educational districts in Lagos state of which Ikeja LGA is under District VI with 25 public secondary schools (13 junior and 12 senior) (19).

\section{Study design and sample size determination}

This was a descriptive cross-sectional study conducted among 420 adolescent school girls in six public secondary schools located in Lagos State. The sample size was calculated using the Cochran formula $\left(n=z^{2} p q / d^{2}\right)$ where $n$ was the estimated minimum sample size; z-level of significance at $95 \%$ confidence level (1.96); $p$ proportion being the knowledge of dysmenorrhea among female students $40.6 \%(0.406)(20)$ in a similar study conducted in Ogun State, Nigeria. $q=(1-p), \quad d=l e v e l$ of precision $(0.05 \%)$. The calculated minimum sample size was 370 , which was adjusted to 420 to make up for non-response and incomplete responses. Respondents were recruited into the study following informed consent from parents and school principals. Those who failed to give informed consent were excluded.

\section{Sampling technique}

A multi-stage probability sampling technique was used to select the respondents from the study population in three stages. Stage 1 comprised of the selection of schools from the list of the 25 public secondary schools in Ikeja LGA, 6 schools were selected by simple random sampling by balloting. In stage 2, one class was selected from each school by simple random sampling by balloting. Stage 3 consisted of the selection of 70 respondents by systematic random sampling using the class list from each of the schools. The sampling interval was the ratio of the total students in the class to the number of students required to be selected from the class. The first respondent was picked by simple random sampling by ballot. Students who were not in school on the day of the selection were replaced by the next student in the sampling frame.

Data collection tool

A pretested self-administered questionnaire was used to obtain data from respondents. The questionnaire was adapted from previous studies, reviewed, and modified accordingly $(21,22)$. It comprised four sections. Section A consisted of socio-demographic and menstrual characteristics. Section B assessed knowledge of menstrual pain, while section $C$ consisted of the perception towards menstrual pain on a five-point Likert scale (strongly agreed, agreed, neutral, disagreed, and strongly disagreed). The fourth section assessed health care seeking behavior and management practices towards menstrual pain. The tool was pretested among 20 students in a similar but different LGA for accuracy and adequacy. The questionnaire was written in the English Language for easy self-administration.

Data Analysis

Data were analyzed with Statistical Package for Social Sciences (SPSS) version 22.0 software. For knowledge questions, correct answers were scored one point, incorrect, and don't know scored zero points. The minimum score was 0 and the highest score was 11. The total score for the knowledge section was calculated by adding all the scores, after which the scores were converted to percentages. Knowledge grade was assigned to each respondent based on their total percentage score. Knowledge was graded as poor $(0-49.9 \%)$ or $(50-100.0 \%)$ good. For the perception questions, the mean score was calculated. Scores below the mean were regarded as negative and above the mean as positive perception. Categorical variables were presented as percentages or proportions while continuous variables were presented as mean \pm standard deviation (SD). The chi-square test was used to determine the association between categorical variables. The level of significance was set at $p \leq 0.05$. 


\section{Results}

Respondents demographics and menstrual history

Table 1 shows the demographic and menstrual characteristics of the respondents. The mean \pm SD age was $14.7 \pm 1.6$ years. About half of the parents of the respondents had tertiary education. More than half $231(55.0 \%)$ of the respondents attained menarche before 12 years of age. The median age of respondents and interquartile range (IQR) was $15(14-16)$ years. The mean \pm SD age at menarche was $12.3 \pm 1.3$ years.

Table 1: Demographic and menstrual characteristics of respondents

\begin{tabular}{|c|c|c|}
\hline Socio-demographic characteristics & Frequency $(\mathrm{N}=420)$ & Percentage (\%) \\
\hline $\begin{array}{l}\text { Age range (years) } \\
10-13 \\
14-17 \\
>17 \\
\text { Mean age } \pm S D=14.67 \pm 1.62\end{array}$ & $\begin{array}{c}104 \\
293 \\
23\end{array}$ & $\begin{array}{c}24.8 \\
69.8 \\
5.4\end{array}$ \\
\hline $\begin{array}{l}\text { Father's Educational level } \\
\text { None } \\
\text { Primary } \\
\text { Secondary } \\
\text { Tertiary }\end{array}$ & $\begin{array}{c}37 \\
19 \\
128 \\
236 \\
\end{array}$ & $\begin{array}{r}8.8 \\
4.5 \\
30.5 \\
56.2 \\
\end{array}$ \\
\hline $\begin{array}{l}\text { Mother's Educational level } \\
\text { None } \\
\text { Primary } \\
\text { Secondary } \\
\text { Tertiary }\end{array}$ & $\begin{array}{c}32 \\
30 \\
165 \\
193\end{array}$ & $\begin{array}{c}7.6 \\
7.1 \\
39.3 \\
46.0 \\
\end{array}$ \\
\hline $\begin{array}{l}\text { Age at menarche } \\
<12 \text { years } \\
>=12 \text { years } \\
\text { Mean } \pm S D=12.26 \pm 1.33 \text { years }\end{array}$ & $\begin{array}{l}231 \\
189\end{array}$ & $\begin{array}{l}55.0 \\
45.0\end{array}$ \\
\hline $\begin{array}{l}\text { Duration of menses } \\
2-3 \text { days } \\
4-5 \text { days } \\
6-7 \text { days } \\
\text { I don't know } \\
\end{array}$ & $\begin{array}{c}130 \\
226 \\
43 \\
21\end{array}$ & $\begin{array}{c}31.0 \\
53.8 \\
10.2 \\
5.0 \\
\end{array}$ \\
\hline $\begin{array}{l}\text { Menstrual cycle length } \\
21 \text { days or less } \\
23-28 \text { days } \\
\text { 28-35 days } \\
\text { Greater than } 35 \text { days } \\
\text { I don't know }\end{array}$ & $\begin{array}{c}74 \\
134 \\
34 \\
2 \\
176\end{array}$ & $\begin{array}{c}17.7 \\
31.9 \\
8.1 \\
0.5 \\
41.9\end{array}$ \\
\hline
\end{tabular}

Knowledge of dysmenorrhea among respondents Table 2 shows the knowledge of respondents about menstrual pain. The majority $356(85 \%)$ of the respondents recognized vomiting or nausea, weakness or tiredness $289(69 \%)$, running stomach $283(67.4 \%)$, while less than half recognized feeling sick $131(31.2 \%)$, headaches $92(21.9 \%)$, back pain $145(34.5 \%)$ as symptoms of dysmenorrhea. Overall, only 106(25.2\%) of respondents had good knowledge of dysmenorrhea. The mean knowledge score was $3.98 \pm 2.35$ with a range of $0.0-11.0$. 
Table 2: Knowledge of respondents about menstrual pain

\begin{tabular}{lcc}
\hline $\begin{array}{l}\text { knowledge of symptoms } \\
\text { (Yes responses only) }\end{array}$ & $\begin{array}{c}\text { Frequency } \\
\text { (N=420) }\end{array}$ & $\begin{array}{c}\text { Percentage } \\
\text { (\%) }\end{array}$ \\
\hline Vomiting or Nausea & 356 & 84.8 \\
Weakness or tiredness & 289 & 68.8 \\
Stomach upset & 283 & 67.4 \\
Mood changes & 213 & 50.7 \\
Loss of appetite & 201 & 47.6 \\
Back pain & 145 & 34.5 \\
Feeling sick & 131 & 31.2 \\
Prevent day-day activities & 119 & 28.3 \\
Headache & 92 & 21.9 \\
Fainting attacks & 76 & 18.1 \\
Absenteeism & 57 & 13.6 \\
\hline Overall knowledge score & & \\
Poor & 314 & 74.8 \\
Good & 106 & 25.2 \\
\hline
\end{tabular}

Perception of respondents towards dysmenorrhea

Table 3 shows the perception of respondents towards dysmenorrhea. About a third 148(35.2\%) of the respondents strongly disagreed that menstrual pain could be natural while more than half $212(50.5 \%)$ strongly agreed that menstrual pain could be due to an underlying disease. Similarly, about $146(34.8 \%)$ strongly agreed and
$69(51.2 \%)$ agreed that one may not be able to concentrate when having menstrual pain. However, more than half $(51.2 \%)$ agreed that menstrual pain is a punishment for eating sugary things and about $41.7 \%$ strongly agreed that abortion could reduce menstrual pain. Overall, about half $(49.8 \%)$ had a good perception of dysmenorrhea.

Table 3: Perception of respondents towards dysmenorrhea

\begin{tabular}{|c|c|c|c|c|c|}
\hline $\begin{array}{l}\text { Perception towards } \\
\text { dysmenorrhea }\end{array}$ & $\begin{array}{l}\text { SA } \\
\text { Freq (\%) }\end{array}$ & $\begin{array}{l}\text { A } \\
\text { Freq }(\%)\end{array}$ & $\begin{array}{l}\text { NS } \\
\text { Freq (\%) }\end{array}$ & $\begin{array}{l}\text { D } \\
\text { Freq (\%) }\end{array}$ & $\begin{array}{l}\text { SD } \\
\text { Freq (\%) }\end{array}$ \\
\hline Menstrual pain could be natural & $19(4.5)$ & $129(30.7)$ & $68(16.2)$ & $56(13.3)$ & $148(35.2)$ \\
\hline $\begin{array}{l}\text { Menstrual pain could be } \\
\text { undesirable }\end{array}$ & $37(8.8)$ & $97(23.1)$ & $129(30.7)$ & $43(10.2)$ & $114(27.1)$ \\
\hline $\begin{array}{l}\text { Menstrual pain could be } \\
\text { bothersome }\end{array}$ & $26(6.2)$ & $107(25.5)$ & $95(22.6)$ & $52(12.4)$ & $140(33.3)$ \\
\hline $\begin{array}{l}\text { Menstrual pain could be due to } \\
\text { an underlying disease }\end{array}$ & $212(50.5)$ & $8(1.9)$ & $11(2.6)$ & $35(8.3)$ & $154(36.7)$ \\
\hline $\begin{array}{l}\text { Menstrual pain is a punishment } \\
\text { for eating sugary things }\end{array}$ & $67(16.0)$ & $215(51.2)$ & $71(16.9)$ & $67(16.0)$ & $0(0.0)$ \\
\hline Abortion reduces menstrual pain & $175(41.7)$ & $5(1.2)$ & $7(1.7)$ & $153(36.4)$ & $80(19.0)$ \\
\hline $\begin{array}{l}\text { Exercise reduces menstrual pain } \\
\text { One may not be able to }\end{array}$ & $51(12.1)$ & $60(14.3)$ & $175(41.7)$ & $49(11.7)$ & $85(20.2)$ \\
\hline $\begin{array}{l}\text { concentrate when having } \\
\text { menstrual pain }\end{array}$ & $146(34.8)$ & $69(51.2)$ & $55(13.1)$ & $113(26.9)$ & $37(8.8)$ \\
\hline $\begin{array}{l}\text { Menstrual pain is common } \\
\text { among virgins }\end{array}$ & $78(18.6)$ & $51(12.1)$ & $47(11.2)$ & $174(41.4)$ & $70(16.7)$ \\
\hline $\begin{array}{l}\text { Overall perception score } \\
\text { Good } \\
\text { Poor }\end{array}$ & $\begin{array}{l}\text { Frequency } \\
209 \\
211\end{array}$ & & $\begin{array}{l}\text { Percentage } \\
49.8 \\
50.2\end{array}$ & & \\
\hline
\end{tabular}

${ }^{*}$ SA-strongly agree; A-agree; NS- not sure; D-disagree; SD-strongly disagree. 
Prevalence of dysmenorrhea and health-seeking practices of respondents

Table 4 shows the prevalence, health-seeking practices, and management of dysmenorrhea among the respondents. The prevalence of menstrual pain was $75.2 \%$ and about $46.5 \%$ reported severe menstrual pain. School absenteeism was observed among $36(11.4 \%)$. The majority $(72.5 \%)$ reported a family history of menstrual pain. Only 30(9.5\%) had ever consulted health workers, while only $5(1.6 \%)$ had ever been admitted for dysmenorrhea. Most $190(60.0 \%)$ reported the usage of medication for pain relief. Panadol/Paracetamol was the most common medication $89(46.8 \%)$. Most of the respondents $73(38.4 \%)$ received medications from their mothers.

Table 4: Prevalence, health-seeking practices and management of dysmenorrhea among respondents

\begin{tabular}{lcc}
\hline Variables (YES Responses only) & $\begin{array}{c}\text { Frequency } \\
\text { (n=420) }\end{array}$ & $\begin{array}{c}\text { Percentage } \\
\text { (\%) }\end{array}$ \\
\hline Experience menstrual pain (MP) & 316 & 75.2 \\
The severity of pain (n=316) & 55 & 17.4 \\
Mild & 114 & 36.1 \\
Moderate & 147 & 46.5 \\
Severe & 36 & 11.4 \\
Ever absent from school due to MP & 229 & 72.5 \\
Family history of MP & 31 & 9.8 \\
Ever consulted health care provider for MP & 5 & 1.6 \\
Admitted for MP & 190 & 60.1 \\
Use of medication to relieve MP & & \\
The drug used for relief of MP* & 89 & 42.4 \\
Panadol/paracetamol & 26 & 12.4 \\
Buscopan & 68 & 32.4 \\
Felvin & 10 & 4.7 \\
lbuprofen & 4 & 1.9 \\
Antibiotics & 13 & 6.2 \\
Herbal drugs & & \\
Sources of medication (n=190) & 73 & 38.4 \\
Mother & 18 & 9.4 \\
Doctor/Nurse & 42 & 22.1 \\
Pharmacist & *Multiple response & 15.6 \\
Self & MP- menstrual pain & \\
Others & & 14.1 \\
\hline \multicolumn{2}{r}{}
\end{tabular}

Figure 1 shows the non-pharmacological painrelief methods among the respondents. Rest was the most common non-pharmacological method used by the respondents for relief from dysmenorrhea $(87.3 \%)$. About half of the respondents $(50.0 \%)$ used a hot water bottle while $19.0 \%$ applied ice. 


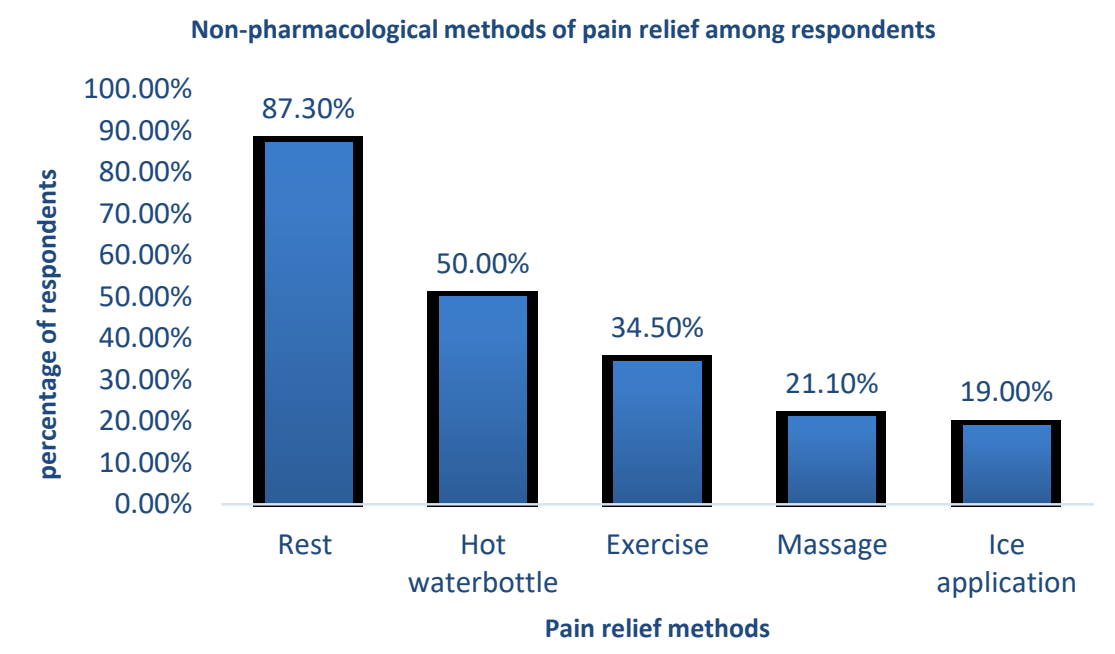

Figure 1: Non-pharmacological pain-relief methods among respondents.

Table 5 shows the association between knowledge of menstrual pain and health care seeking behavior among respondents who had dysmenorrhea. There was a statistically significant relationship between knowledge of dysmenorrhea and health care seeking behavior of the respondents $(p=0.004)$.

Table 5: Association between knowledge of menstrual pain and health care seeking behavior among respondents who had dysmenorrhea.

\begin{tabular}{|c|c|c|c|c|}
\hline \multirow[t]{2}{*}{ Knowledge grade } & \multicolumn{2}{|c|}{ Health care seeking } & \multirow[t]{2}{*}{ Total } & \multirow{2}{*}{$\begin{array}{l}\text { Test of } \\
\text { statistics }\end{array}$} \\
\hline & No & Yes & & \\
\hline Poor & 208(93.3) & $15(6.7)$ & $223(100.0)$ & $X^{2}=8.144$ \\
\hline Good & $77(82.8)$ & 16(17.2) & $93(100.0$ & $P=0.004$ \\
\hline Total & $285(90.2)$ & $31(9.8)$ & $316(100.0)$ & \\
\hline
\end{tabular}

\section{Discussion}

The mean age at menarche in this study (12.26 \pm 1.33 years) was higher than that reported in a similar study among University students in Ogun State, Nigeria which was 10.7years (20), but lower than that reported in Ibadan, Nigeria $13.34 \pm 4.1$ years (8). A study in India reported $13.3 \pm 1.3 y e a r s(21)$. This study found a prevalence of $75.2 \%$ of dysmenorrhea among the respondents. This was similar to the findings in previous studies in Ogun $(78.1 \%)(20)$, Nnewi $(70.4 \%)(10)$, and Ghana $(74.4 \%)(23)$. Higher prevalence had been reported in Northern Ghana (83.6\%), (24), and Sri Lanka (84\%) (9). While much higher prevalence has been reported in Ibadan, Nigeria (87.3\%). It can be inferred that dysmenorrhea is very common among adolescent females. The high prevalence of dysmenorrhea calls for the education of adolescent girls on the effective management of dysmenorrhea.

Knowledge is very important for an individual to seek health care for the effective management of a condition. This study found that only $25.2 \%$ of respondents had good knowledge about dysmenorrhea. Similarly, a study in Ibadan, Nigeria reported poor knowledge among respondents (8). A study among university students in Shahid Sadoughi, Iran reported that only $6.3 \%$ had good knowledge of menstrual pain (MP) (5). Similarly, a survey in Dhaka, Bangladesh found that $88 \%$ of respondents did not have good knowledge about menstruation (7). However, our finding is lower compared to a similar study in Ogun state, Nigeria which reported $40.6 \%$ of respondents with good knowledge (20). The poor knowledge found in our study might be because the study was conducted among secondary school students, unlike the comparison studies which were among university students.

Generally, respondents had various perceptions of dysmenorrhea in this study. About one-third of the respondents strongly disagreed that menstrual pain could be natural while more than half strongly agreed that menstrual pain could be 
due to an underlying disease. However, more than half of the respondents thought that dysmenorrhea is a punishment for eating sugary things, and about half strongly agreed that abortion could reduce menstrual pain. This is a reflection of the wrong perception probably due to a lack of sexuality education among the students. Appropriate sexuality information is required for adolescents to understand that dysmenorrhea is not a punishment for eating sugary things and that abortion is not a treatment for it. A wrong perception of dysmenorrhea has been reported by previous studies $(10,25,26)$. A previous study had reported that adolescents with poor perception about menstruation had higher morbidity (27).

In this study, almost half of the respondents reported having severe dysmenorrhea similar to previous studies in Nnewi, Nigeria, (10), and Turkey (28). These studies found that dysmenorrhea was largely rated as moderate or severe by the respondents. About one-tenth of respondents in this study reported absenteeism from school due to dysmenorrhea, and this could negatively impact their academic performance, especially during examinations. The rate of absenteeism in this study is similar to a study in Ghana $(9.2 \%),(29)$ but differs from similar studies in Ogun state, (46.3\%), (20) Oyo State, Nigeria (44.1\%) (8) and Sri Lanka (44\%) (30) This difference observed are probably due to the different study populations involved. It has been documented that about $10-15 \%$ of women of reproductive age experience monthly dysmenorrhea which is severe enough to affect normal daily functions at work or school $(31,32)$. The majority of the respondents $(72.5 \%)$ reported a family history of dysmenorrhea. This was higher than what was reported in a study in Northwestern Ethiopia where about half $(50.6 \%)$ of the respondents had a family history of dysmenorrhea (4). Positive family history has been listed as a risk factor for dysmenorrhea (33). Despite the high prevalence of dysmenorrhea found among the respondents in this study, only a few $(10 \%)$ had ever consulted health care providers for dysmenorrhea, of which about $2 \%$ had been hospitalized for treatment. The study in Ogun, Nigeria reported that $7.9 \%$ consulted healthcare providers (20). Another study in Ibadan, Nigeria reported 3.2\% (8). However, a study in Enugu, Nigeria reported that $16 \%$ of adolescent girls sought medical advice regarding dysmenorrhea (34).

The low prevalence of healthcare-seeking behavior generally might be due to the cultural perception and secrecy of menstruation and the associated pain. The majority of women believed that dysmenorrhea was normal and should not be discussed (35). Also, it was culturally believed that menstrual pain was associated with fertility and the severity of dysmenorrhea was directly proportional to the fertility of individuals. Studies have reported the influence of cultural background on health care seeking behavior of dysmenorrhea $(36,37)$. A study found that $84 \%$ of respondents believed that dysmenorrhea was a natural thing for them and will stop after marriage (9).

This study investigated the different pharmacological and non-pharmacological agents with which respondents managed dysmenorrhea. About sixty percent of the respondents used medications to relieve menstrual pain, higher than the study in Northwestern Ethiopia (36.3\%) (4). Another study in Nnewi, Nigeria reported that $44.7 \%$ of the affected students took medications (10). Panadol/Paracetamol was the most commonly used drug for pain relief in this study similar to the study in Sri Lanka (9). Felvin, a non-steroidal antiinflammatory drug (NSAID) was the second commonly used drug by respondents. This finding was similar to a study in Ibadan, Nigeria where the majority of respondents used paracetamol (8). The majority of the respondents in the present study were taking treatment from their mothers, and pharmacists. Studies have shown that the majority of women self-medicate with over-the-counter drugs to manage dysmenorrhea $(38,39)$. The use of over-thecounter medication is however associated with lots of risks such as worsening of existing peptic ulcers with the use of NSAIDs. Also, drug-drug interaction is a potential danger associated with self-medication (20).

This study found that most of the respondents used rest, hot water bottles, and exercise as nonpharmacologic treatments for dysmenorrhea. Similarly, a study in Baghdad reported the restriction of physical activities in $84.2 \%$ of the respondents during menstruation (39). The use of hot water bottles has also been reported by other studies $(10,11)$. Another study reported that physical activities such as walking around were effective in managing primary dysmenorrhea. The proportion of respondents with good knowledge who sought healthcare was higher compared with the proportion of respondents with poor knowledge who sought healthcare. This implies that better knowledge of dysmenorrhea among adolescents would improve their 
healthcare-seeking behavior. Other causes of dysmenorrhea such as infective endometritis, which may be a consequence of STI, were not excluded. Furthermore, the age of coitarche was not assessed. These are limitations of this study.

\section{Conclusion}

Despite the high prevalence of dysmenorrhea found in this study, knowledge, and perception was sub-optimal. Health seeking behavior of the respondents was also poor. Improving adolescent's knowledge about dysmenorrhea through health education on reproductive health could positively influence their healthcareseeking behavior.

\section{List of abbreviations}

LCDA: Local council development area

LGA: Local Government area

SD: Standard deviation

SPSS: Statistical package for social sciences

IQR: Interquartile range

\section{Declarations}

Ethics approval and consent to participate Ethical approval was obtained from the Human Research and Ethics Committee (HREC) of the Lagos University Teaching Hospital. (ADM/DCST/HREC/APP/326) Permission was also obtained from the school principal of each school. Written informed consent was obtained from each respondent with the assurance of confidentiality of information, the right to withdraw from the study at any point in time, and voluntariness of participation.

\section{Consent for publication}

The authors hereby give consent for the publication of our work under the creative commons CC Attribution-Noncommercial 4.0 license.

\section{Availability of data and materials}

The data and materials associated with this research will be made available by the corresponding author upon reasonable request.

\section{Competing interests}

The authors have declared no conflict of interest.

\section{Funding}

The authors received no research funding.

\section{Authors' contributions}

EOO was responsible for the concept, study design, literature search, data review, analysis, drafting, and review of the manuscript. AOO was responsible for the concept, study design, literature search, data collection, review, and review of the manuscript. AOO participated in drafting and critical review of the manuscript. OQB participated in drafting and critical review of the manuscript. All authors approved the final manuscript and declare that the manuscript represents honest work.

\section{Acknowledgment}

None.

\section{References}

1. Mathew A, Varghese DM, Shaju M V, Joseph N, Tamrakar A. Dysmenorrhea among Adolescent Girls in Selected Schools at Mangalore with View to Develop and Distribute an Information Booklet. IOSR Journal of Nursing and Health Science (IOSRJNHS.) 2015;4(1):34-39. https://doi.org/10.9790/1959-03621620

2. Chandrima FA. A survey on knowledge and awareness of dysmenorrhea among the female students of East West University. A dissertation submitted to the Department of Pharmacy, East West University, Aftabnagar, Dhaka in partial fulfillment of the requirements for the degree of Bachelor of Pharmacy 2013. Pages $1-58$. https://doi.org/10.22606/adap.2018.33005

3. Onur O, Kaygusuz I, Gumus I, Derbent A, Simvali S, Urun E. Impact of home based exercise in people with primary dysmenorrhea. South African J Obstet Gynecol. 2012;18(1):528.

4. Gebeyehu M, Mekuria A, Tefera Y, Andarge $D$, Debay $Y$, Bejiga $G$, et al. Prevalence, impact, and Management Practice of Dysmenorrhea among Prevalence , Impact, and Management Practice of Dysmenorrhea among University of Gondar Students, Northwestern Ethiopia: A Cross-Sectional Study. International Journal of reproductive medicine. 2017;1-8. https://doi.org/10.1155/2017/3208276

5. Baghianimoghadam $\mathrm{MH}$, Alavijeh, Loo AM, Falahzadeh $\mathrm{H}$, Alavijeh MM. A Survey about the Prevalence of Dysmenorrhea in Female Students of Shahid Sadoughi University of Medical Sciences and their knowledge and practice toward it. Journal of Health Researches. 2012; 1(2): 26-31. http://jhr.ssu.ac.ir 
6. World Health Organization. Health for the World's adolescents. A second chance in the second decade. Apps.who.int. Accessed $5^{\text {th }}$ September 2020

7. Parvin N, Parvin B, Haque MM, Islam MS. Knowledge on Menstruation Among Adolescent School Girls in a selected area of Dhaka City. Chattagram Maa-O-Shishu Hospital Medical College Journal 2016;15:1. https://doi.org/10.3329/cmoshmcj.v15i1.2875 $\underline{9}$

8. Owonikoko MK, Okunlola MA, Ogunbode OO, Enabor OO, Oluwasola TAO, Arowojolu AO. Menstrual Health of In-School Adolescents in Ibadan: Knowledge, Attitudes and Consequences Nigerian Medical Practitioner 2009; 55(5):80-83. https://doi.org/10.4314/nmp.v55i5.45437

9. Sewvandi H, Sampath M, Wijesiri K, Suresh TS. Knowledge and attitudes towards dysmenorrhea among adolescent girls in an urban school in Sri Lanka. Nursing and Health Sciences 2013;15: 58-64. https://doi.org/10.1111/j.14422018.2012.00736.x

10. Egenti NB, Onuorah UC, Ebenebe UE, Adogu POU, Egwuatu CC. Perception of Dysmenorrhea and Its Relationship to School Activities among Senior Secondary School Students in Nnewi, Nigeria. International STD Research \& Reviews 2016;4(2):1-8. https://doi.org/10.9734/isrr/2016/26487

11. Kumar KS, Konjengbam S, Devi HS. Dysmenorrhea among higher secondary schoolgirls of Imphal West district, Manipur: A cross-sectional study. J Med Soc 2016;30:3843. https://doi.org/10.4103/0972-4958.175849

12. Agboola A. Textbook of Obstetrics and Gynecology for Medical Students, 2nd Edition. Heinemann Educational Books Plc, Ibadan, Nigeria.; 2006.

13. Bewley S, Cheong Y, Creighton S, Dobbs S, Gebbie A, Gupta J, et al. Gynecology by ten teachers. 19th edition. Published by Bookpower Edition of Nineteen Edition, India,. 2011.:40-42.

14.Ju, $\mathrm{H}$, Jones, $\mathrm{M}$. and Mishra, $\mathrm{G}$. The prevalence and risk factors of dysmenorrhea. Epidemiol Rev.2013;36(1):104-113. https://doi.org/10.1093/epirev/mxt009

15. Campbell MA, McGranth PJ. Use of medication by adolescents for the management of menstrual discomfort. Arch Pediatr Adolesc Med. 1997;151:905. https://doi.org/10.1001/archpedi.1997.02170
460043007

16. Shferaw MT, Wubshet $M$, Tegabu $M$. Menstrual problems and associated factors among students of Bahar Dar University, Amhara National Regional State, Ethiopia. Pan African Med Journal. 2014;17(246):1. https://doi.org/10.11604/pami.2014.17.246.2 230

17. Wong LP. Attitudes towards dysmenorrhoea, impact and treatment seeking among adolescent girls: A rural school-based survey. Aust J Rural Heal. 2011;19:218-223. https://doi.org/10.1111/j.14401584.2011.01213.x

18. Ogunfowokan AA, Babatunde OA. Management of primary dysmenorrhea by school adolescents in Ile-Ife, Nigeria. J Sch Nurs. $\quad 2010 ; 26: 131-136$. https://doi.org/10.1177/1059840509349723

19. Education District -Lagos State Government. Available at www.lagoseducationdistrict6 [Accessed 2018 May 29].

20.Farotimi AA, Esike J, Nwozichi CU, Ojediran TD, Ojewole FO. Knowledge, Attitude, and Healthcare-Seeking Behavior Towards Dysmenorrhea among Female Students of a Private University in Ogun State, Nigeria. 2015;4(1). https://doi.org/10.4103/2278960x.153524

21.Shanbnam O, Hajar S, Khyrunmsa S. The Relationship between Dysmenorrhea and Menstrual attitudes among adolescent and young females in urban area, South India. World Med Sci. 2015;12(1):56-61.

22. Omidvar S, Salmalian H, Begum K. The Relationship Between Dysmenorrhea and Menstrual Attitudes among Adolescent and Young Females in Urban Area, South India. World Journal of Medical Sciences 2015; 12 (1): 56-61.

23.Wong LP. Premenstrual syndrome and dysmenorrhea: Urban-Rural and multiethnic differences in perception impact and treatment seeking. J Pediatr Adolesc Gynecol. 2011;24(5):272-273. https://doi.org/10.1016/j.jpag.2011.03.009

24. Ameade E, Amalba A, Mohammed B. Prevalence of dysmenorrhea among university student in Northern Ghana; its impact and management strategies. BMC Women's Heal 2018;18(39). https//doi.org/101186/s12905-018-0532-1. https://doi.org/10.1186/s12905-018-0532-1

25. Titilayo A, Agunbiade OM, Banjo O, Lawani A. Menstrual discomfort and its influence on daily academic activities and psychosocial 
relationship among undergraduate females in Nigeria. Tanzania J Heal Res. 2009;11:181188. https://doi.org/10.4314/thrb.v11i4.50173

26. Wong LP. Premenstrual syndrome and dysmenorrhea: Urban-Rural and multiethnic differences in perception impact and treatment seeking. J Pediatr Adolesc Gynecol. 2011;24(5):272-273. https://doi.org/10.1016/j.jpag.2011.03.009

27. Houston, A.M.A., A. Huang and Z. D'Angelo, L.J. Knowledge, attitudes and consequences of menstrual health in urban adolescent females. J Pediatr Adolesc Gynecol. 2006;19(4):271-275.

28. Potur DC, Bilgin NC, Komurcu N. Prevalence of dysmenorrhea in university students in Turkey: Effect on daily activities and evaluation of different pain management methods. Pain Manag Nurs. 2014;15(4):768777. DOI: 10.1016/j.pmn.2013.07.012. https://doi.org/10.1016/j.pmn.2013.07.012

29. Gumanga SK, Kwame-Aryee R. Prevalence and severity of dysmenorrhea among some adolescent girls in a secondary school in Accra Ghana. Postgr Med J Ghana 2012;116.

30.Wijesiri HS, Suresh TS. Knowledge and attitudes towards dysmenorrhea among adolescent girls in an urban school in Sri Lanka. Nurs Heal Sci 2013;1558-64. https://doi.org/10.1111/j.14422018.2012.00736.x

31. Olowokere AE, Oginni MO, Olajubu AO, William AE, Irinoye $O O$. Menstrual disorders: The implications on health and academic activities of female undergraduates in a Federal university in Nigeria. J Nurs Educ $\mathrm{Pr}$ 2014;4126-35 35. 2014;4:126-135. https://doi.org/10.5430/inep.v4n5p126

32. Dawood MY. Primary dysmenorrhea: Advances in pathogenesis and management. Obs Gynecol 2006;108428-4. 2006;108:4284.

33.Pejcic A, Jankovic S. Risk factors for dysmenorhea among young adult female university students. Ann $1^{\text {st }}$ Super Sanita 2016; 52(1): 98-103. DOI: 10.4415/ANN_16_01_16

34. Nwankwo TO, Aniebue UU, Aniebue PN. Menstrual disorders in adolescent school girls in Enugu, Nigeria. J Pediatr Adoles Gynecol. 2010;23:358-363. https://doi.org/10.1016/j.jpag.2010.04.001

35. Wong LP, Khoo EM. Menstrual-related attitudes and symptoms among multi-racial
Asian adolescent females. Int $\mathrm{J}$ Behav Med 2011; 18:246-53. https://doi.org/10.1007/s12529-010-9091-z

36. Lovering $S$. Cultural attitudes and beliefs about pain. J Transcult Nurs. 2006;17:389395. https://doi.org/10.1177/1043659606291546

37. Aziato L, Adejumo O. An ethnographic exploration of post-operative pain experiences among Ghanaian surgical patients. J Transcult Nurs. 2014;8:1-7. https://doi.org/10.1177/1043659614526246

38. Busari AO. Menstrual knowledge and health care behaviour among adolescent girls in rural Nigeria. Int J Appl Sci Technol. 2012;2:149154.

39. Sadiq MA, Salih AA. Knowledge and practice of adolescent females about menstruation in Baghdad. J Gen Pr. 2013;2:1-4. https://doi.org/10.4172/2329-9126.1000138 